\title{
A relation between extreme daily precipitation and extreme short term precipitation
}

\author{
Yanina L. Romero • J. Bessembinder • \\ N. C. van de Giesen - F. H. M. van de Ven
}

Received: 29 December 2008 / Accepted: 29 June 2010 / Published online: 14 December 2010

(C) The Author(s) 2010. This article is published with open access at Springerlink.com

\begin{abstract}
The Royal Netherlands Meteorological Institute (KNMI) has published the KNMI'06 climate scenarios in 2006. These scenarios give the possible states of the climate in The Netherlands for the next century. Projections of changes in precipitation were made for a time scale of 1 day. The urban drainage sector is, however, more interested in projections on shorter time scales. Specifically, time scales of $1 \mathrm{~h}$ or less. The aim of this research is to provide projections of precipitation at these shorter time scales based on the available daily scenarios. This involves an analysis of climate variables and their relations to precipitation at different time scales. On the basis of this analysis, one can determine a numeric factor to translate daily projections into shorter time scale projections.
\end{abstract}

\section{Introduction}

Rising temperatures are generally expected to be accompanied by increases in rainfall intensities at mid- and high latitudes (Meehl et al. 2005, 2007). Urban areas are especially vulnerable to increased rainfall intensities, especially during convective summer storms (Smith et al. 2002; Waters et al. 2003; Kundzewicz et al. 2007).

Y. L. Romero $(\varangle)$ · N. C. van de Giesen · F. H. M. van de Ven Water Management, Delft University of Technology,

Stevinweg 1, 2628 CN Delft, The Netherlands

e-mail: p.bronkhorst8@upcmail.nl

J. Bessembinder

Royal Netherlands Meteorological Institute, Wilhelminalaan 10,

3732 GK De Bilt, The Netherlands

F. H. M. van de Ven

Deltares, Rotterdamseweg 185, 2629 HD Delft, The Netherlands

Present Address:

Y. L. Romero

Waterboard Aa and Maas, Pettelaarpark 70, 5216 PP 's-Hertogenbosch, The Netherlands 
Regional impacts will differ from average climate predictions, which make regional studies necessary, such as this one for The Netherlands. The goal of this study is to examine the impact of possible climate change on rainfall intensities at a time scale of $1 \mathrm{~h}$.

The Royal Netherlands Meteorological Institute (KNMI) developed four KNMI'06 climate scenarios that provide information on projected changes in daily precipitation. These scenarios are based on a large number of global and regional climate models. For urban drainage design, daily precipitation is less relevant; critical response times of storm sewerage and surface drains are in the order of minutes to hours (Smith et al. 2002; Ntelekos et al. 2008). Regional climate model output on peak precipitation for shorter time scales is not (yet) reliable enough to allow for a publishable estimate. Therefore a new method was developed to study the relation between daily and shorter time interval precipitation from historical data. The objective is to use variables available in the KNMI'06 scenarios to obtain conditional relations between daily and shorter interval precipitation. If it can be assumed that these relations will remain more or less the same in the future, estimates could also be made for short term peak precipitation in the future.

\section{Methods and materials}

The applied methodology involves selection of climate variables that are likely to affect rainfall intensities at the desired short time scales, acquisition and selection of historical data, and the analysis of correlations between variables available in the KNMI'06 scenarios and the ratio of $1 \mathrm{~h}$ and daily precipitation. The selection of the KNMI'06 scenarios is based on two steering parameters: change in global mean temperature and change in air circulation pattern. This resulted in four scenarios shown in Fig. 1. The scenarios span a large part of the uncertainty about our future climate, and they are a translation of larger scale climate change projections to climate change in The Netherlands. It was first assumed at KNMI in 2007 that extreme hourly rainfall would change in the same way as the extreme daily rainfall. This research aimed at checking this hypothesis and providing a further elaboration of the KNMI'06 scenarios with information about hourly precipitation extremes and quantification thereof. Explanatory climate variables that could be linked to

Fig. 1 The Four KNMI'06 Climate Scenarios (Royal Netherlands Meteorological Institute 2006)

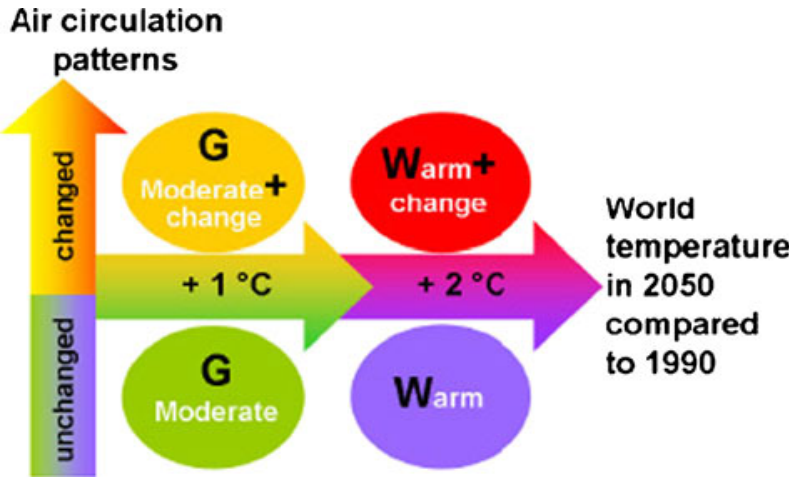


the steering parameters in the KNMI'06 scenarios were selected to this end. These variables were then analyzed with hourly and daily precipitation.

\subsection{Selection of climate variables}

The main variables that, a priori, could have an influence on extreme precipitation include:

- $\quad$ wind (speed, direction) or wind at higher altitudes

- air temperature

- humidity

- air pressure

- $\quad$ sea-surface temperature (The Netherlands)

Based on literature study and expert consultation, wind direction and maximum daily air temperature were chosen to be used for further analysis.

Some studies conducted in the Iberian Peninsula and the British Isles have led to the conclusion that a correlation exists between wind or atmospheric circulation and extreme precipitation (Phillips and McGregor 2001; Gallego et al. 2005; Mitchell and Phillips 2006). KNMI concluded that wind direction but not wind velocity was an indicator for precipitation (Overeem et al. 2008). Wind direction or, better, geostrophic circulation (wind at higher altitudes) could be an explanatory climate variable linked with differences between the KNMI'06 scenarios. The wind direction at higher altitudes determines from where air masses are transported to The Netherlands, for example from over the ocean (generally moist) or over land (in summer often dry and warm). Rain cloud formation is often caused by southwesterly circulation, corresponding to a limited range of G-West values. Under such circulation patterns, warmer air from the Mediterranean region is transferred to The Netherlands after absorbing moisture over the North Sea. At the surface the wind direction can be different, due to friction. G-west is a measure used at KNMI to quantify geostrophic wind from westerly direction. G-West is the magnitude of the velocity of the wind coming from the west at $270^{\circ}$. A negative value of $-2.6 \mathrm{~m} / \mathrm{s}$ would correspond to a wind coming from the east at $90^{\circ}$ with a speed of $2.6 \mathrm{~m} / \mathrm{s}$. G-west is thought to be an important explanatory variable for precipitation. A data series was compiled based on data from the ERA-40 database (Lenderink and van Meijgaard 2008) for The Netherlands and they are available from 1958. G-west is determined six times daily and is derived from surface pressure. For this study, average daily values are used.

Warm weather has been found to be key for short duration, high intensity rainstorms (Doswell et al. 1996; Chang 1998; Smith et al. 2002). Former analysis showed that the annual maxima for $24 \mathrm{~h}$ and $4 \mathrm{~h}$ mostly occurred during the months May-September. KNMI experts also indicated that maximum daily temperature could be an explanatory climate variable that can be linked with differences between the KNMI'06 climate scenarios. Warmer air can contain more moisture which is favorable for precipitation. Maximum daily temperature can be used instead of average daily temperature because it can easily be linked to KNMI'06 climate scenarios, which provide average daily temperature. Based on observations over the last 30 years, the difference between maximum, minimum, and average daily temperature did not really change. It is assumed that this relation between maximum, minimum, and average temperatures will not change in the future. 
2.2 Selection and validation of historical data

KNMI has an automatic and manual rain gauge network to record precipitation. Until the 1970s, mechanical pluviographs were used as automatic rain gauges. Pluviographs have since then been replaced by electronic rain gauges. At the automatic stations, each hour recordings are made, at the manual stations only once per day. The 60-min precipitation data used in this paper were recorded with automatic rain gauges because the 60 -min precipitation data recorded before 1980 have not yet been digitized. The quality of the 60 -min automatic measurements was checked by comparing their daily sums with 24-h manual measurements.

At KNMI in The Netherlands, historical precipitation data is available for daily, 1$\mathrm{h}$ and 10-min observational time segments. Many years of historical data are available for precipitation amounts on a daily basis. In comparison, fewer years of data are available on an hourly basis. Less than 25 years of data are available for shorter time intervals including 15 -min or less. Five to $10 \mathrm{~min}$ data is the most interesting for urban drainage and urban water management. Urban water managers wish to have information about 10 -min precipitation recordings as the characteristic time of urban runoff processes is of that order of magnitude (Graf 1977; Smith et al. 2002). However, 10-min recordings are not validated and/or the available number of years is too limited to cover most of the natural variability.

That is why it was decided to use validated 60 -min precipitation data recorded at the station De Bilt in The Netherlands for this research. The station De Bilt was chosen for the long (>50 years) time series available for both daily and hourly precipitation. A minimum of 30 years of data is generally used to describe most of the natural variability, but for extreme values preferably even larger time series are used (Heijboer and Nellestijn 2002). In addition, De Bilt is a non-coastal location where there is hardly or no effect of seawater temperatures on extreme precipitation therefore making it easier to link extreme precipitation to air temperature and Gwest. It is also recognized that urban areas may exacerbate formation of summer storms (Ntelekos et al. 2008) due to the urban heat island and that this effect is also not reflected in the time series of De Bilt.

\section{Analysis}

The analysis consists of three parts. First, an exploratory analysis of the correlation between temperatures and precipitation extremes is put forward. Second, a similar analysis concerning the correlation between circulation patterns (G-west) and precipitation extremes is given. Finally, the ratio between daily and hourly precipitation as function of maximum daily temperature and G-west is given, which allows for temporal downscaling on the basis of climate projections.

\subsection{Temperature and precipitation extremes}

A visual technique was used to obtain a first idea of how maximum daily temperature and G-west correlate with daily precipitation. Scatter plots were made using other climate variables to obtain a sense of when and under which circumstances extreme precipitation occurs. Raw data hardly show a relation between daily precipitation and maximum daily temperature. 
Based on the data series 1958-2006, Fig. 2. presents a scatter plot of maximum daily temperature versus maximum hourly precipitation per day. It shows no clear relation between precipitation and temperature. However the maximum values seem to have some relation with temperature. An interesting point is that extreme hourly precipitation amounts of more than $20 \mathrm{~mm}$ (shown in Fig. 2) do indeed occur during warmer temperature days of $20^{\circ} \mathrm{C}$ and above. However in a plot of the annual maximum precipitation against temperature, there is no clear relation. Annual maxima often occur during the summer half of the year with relatively high temperature (STOWA 2004). The main focus of this research is extreme precipitation and therefore these months will be analyzed further.

\subsection{Circulation and precipitation}

The second explanatory variable for climate change in The Netherlands is G-west. As mentioned earlier, G-west is derived from surface pressure. Figure 3 shows a scatter

\section{Maximum Daily Temperature vs. Maximum Hourly Precipitation Per Day}

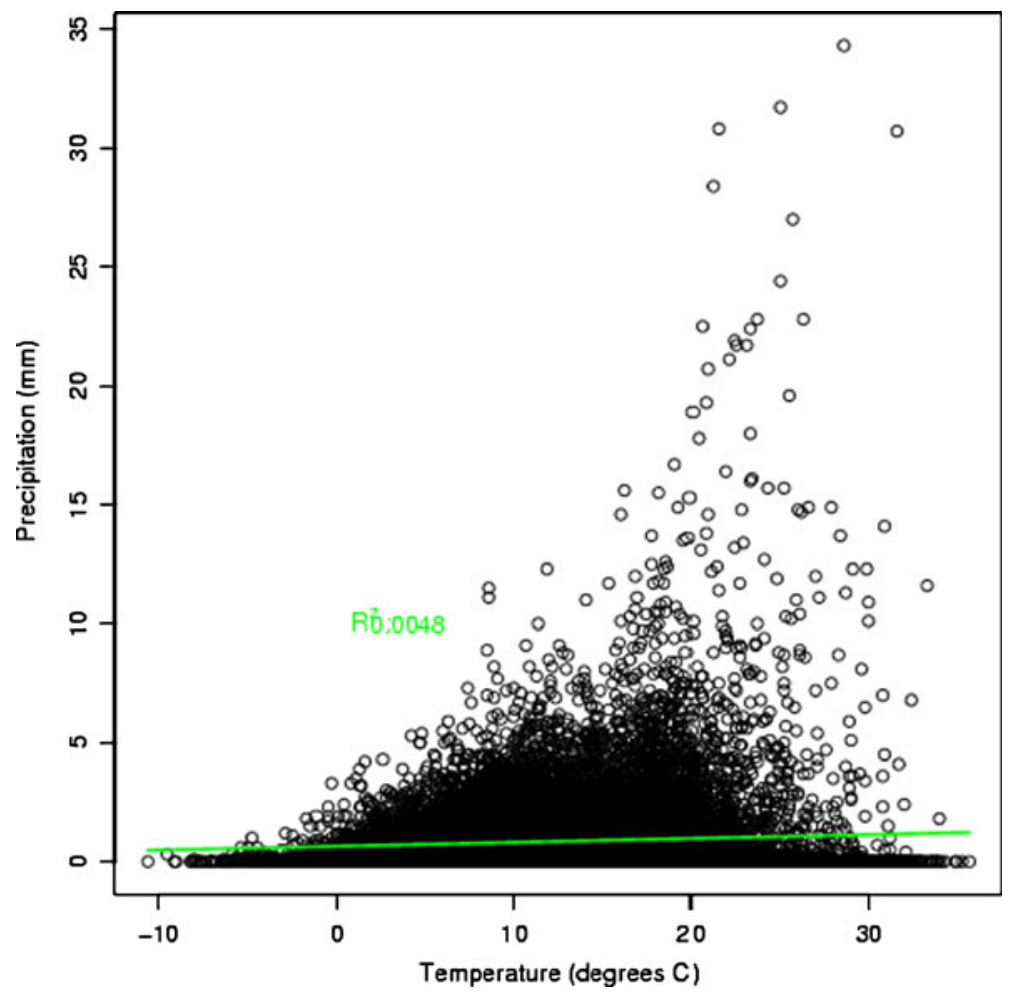

Fig. 2 Maximum daily temperature vs. maximum hourly precipitation per day for De Bilt 1958-2006. Green line is the linear regression value of 0.0048 
Average Daily G-west vs. Daily Precipitation (JJA)

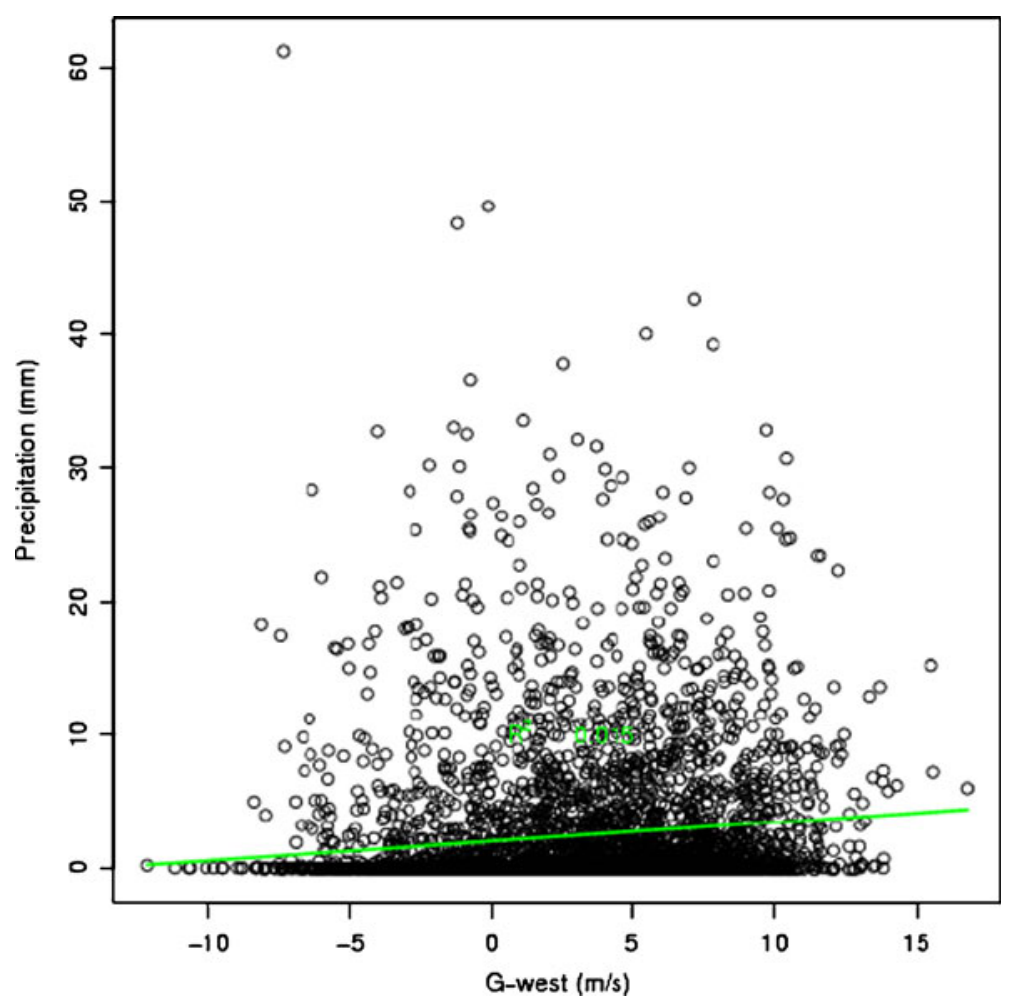

Fig. 3 Average daily G-west vs. daily precipitation for summer months (De Bilt 1958-2006). Green line is the linear regression with a regression coefficient $\mathrm{r}^{2}=0.015$

plot of G-west and daily precipitation for De Bilt during summer months June, July, and August. Figure 4 is a plot of G-west and maximum hourly precipitation per day.

Both Figs. 3 and 4 show that extreme daily precipitation and extreme maximum hourly precipitation per day occurred with a $\mathrm{G}$-west value close to $0 \mathrm{~m} / \mathrm{s}$. This suggests that daily maxima and hourly maxima may occur during the same or similar meteorological conditions. Correlation between maximum daily temperature and G-west was not significant (>95\% confidence). Therefore we can assume for the remainder of this analysis that maximum daily temperature and G-west are independent of each other.

\subsection{Correlations between daily and hourly precipitation and climate variables}

Since we are interested in extreme hourly rainfall and we only have information about the change of extreme daily rainfall in case of climate change we decided to investigate the ratio between maximum hourly versus daily rainfall in relation to temperature and G-west. We also determined the quantiles. Primarily the upper quantiles: $90 \%, 95 \%$, and $99 \%$ are of interest to us, as these indicate extremes of the recorded daily and hourly precipitation versus maximum daily temperature and versus G-west respectively. 


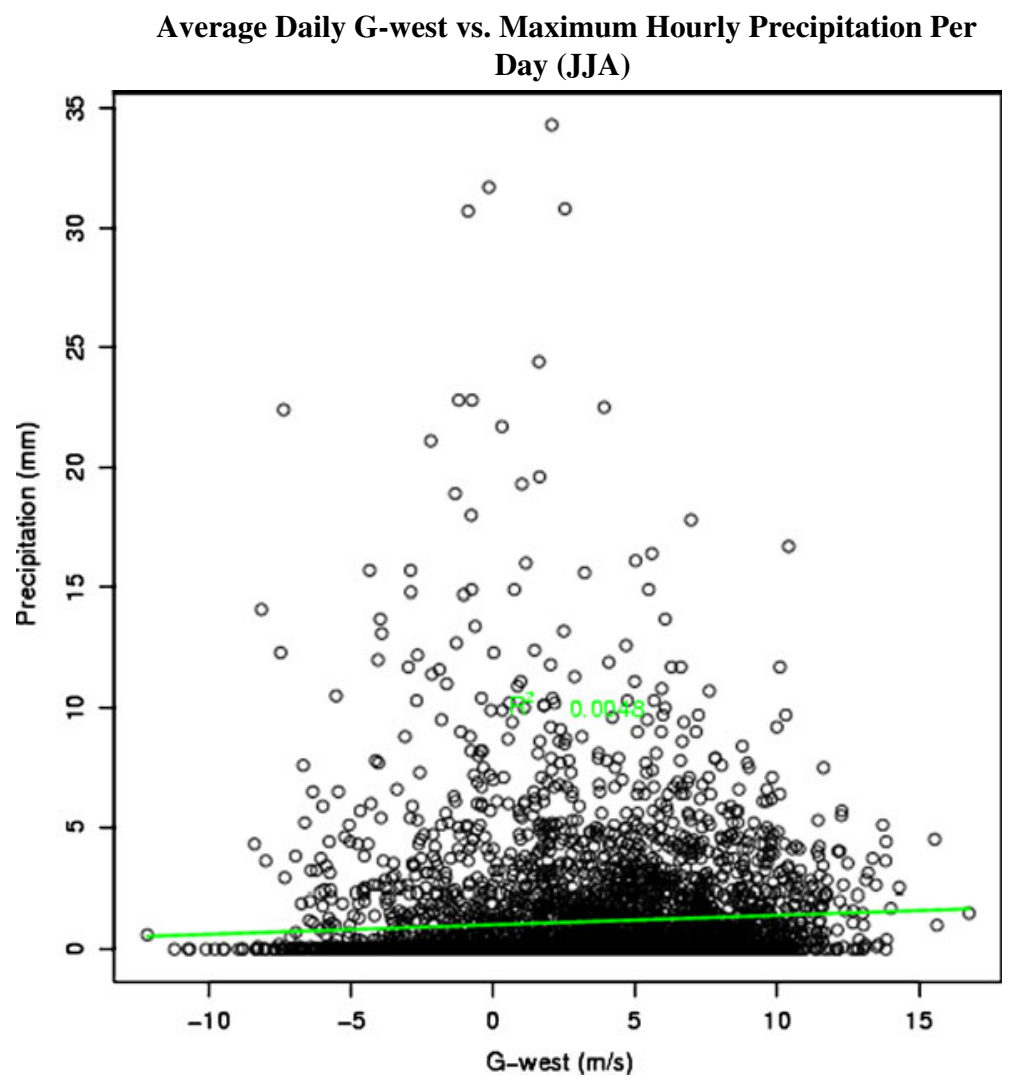

Fig. 4 Average daily G-west vs. maximum hourly precipitation per day for summer months (De Bilt 1958-2006). Green line is the linear regression value with a regression coefficient $\mathrm{r}^{2}=0.0048$

Figure 5 shows a frequency representation (lower part of figure) of two climate parameters: maximum daily temperature and amount of precipitation (only wet days). The data represent the summer months May, June, July, August, and September for the years 1958-2006. In the upper half of Fig. 5, lines indicate the percentage of data that are below the line (90\% quantiles equals $90 \%$ below, 10\% above). Figure 6 shows maximum daily temperature versus maximum hourly precipitation per day. Both figures allow for a comparison of maximum daily temperature with hourly and daily precipitation.

Below the horizontal axis, a histogram represents the frequency of the data. For both figures, more hours or days of precipitation occur with a maximum daily temperature value between $15^{\circ} \mathrm{C}$ and $20^{\circ} \mathrm{C}$, at higher temperatures maximum hourly precipitation seems to increase with temperature. This is not clearly the case for daily precipitation. This is in line with our expectation that extreme precipitation is generally occurring during warmer days.

Figure 7 presents a frequency representation of daily G-west and precipitation (only wet days). Figure 8 shows G-west versus maximum hourly precipitation per day. Both plots show that more hours or days of precipitation occur with a G-west value of approximately $5 \mathrm{~m} / \mathrm{s}$. 


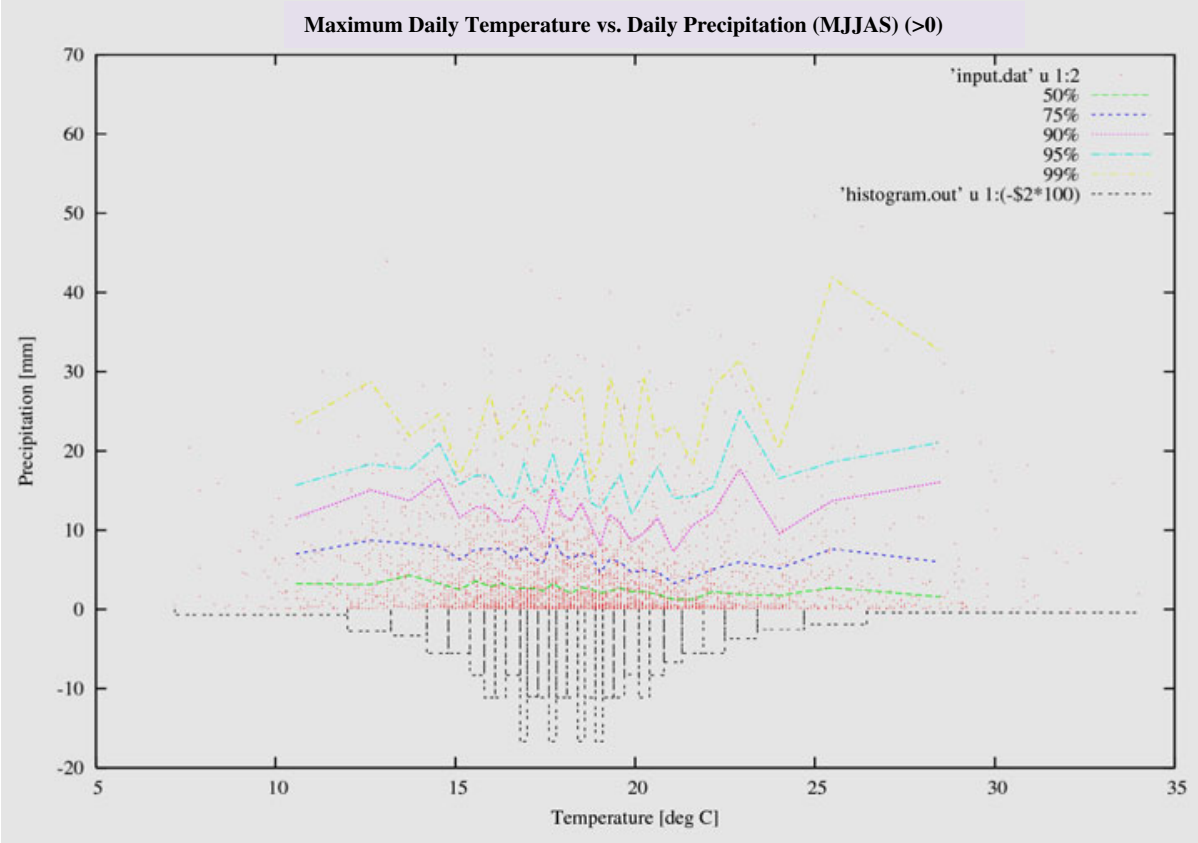

Fig. 5 Maximum daily temperature vs. daily precipitation for summer months (May-September)

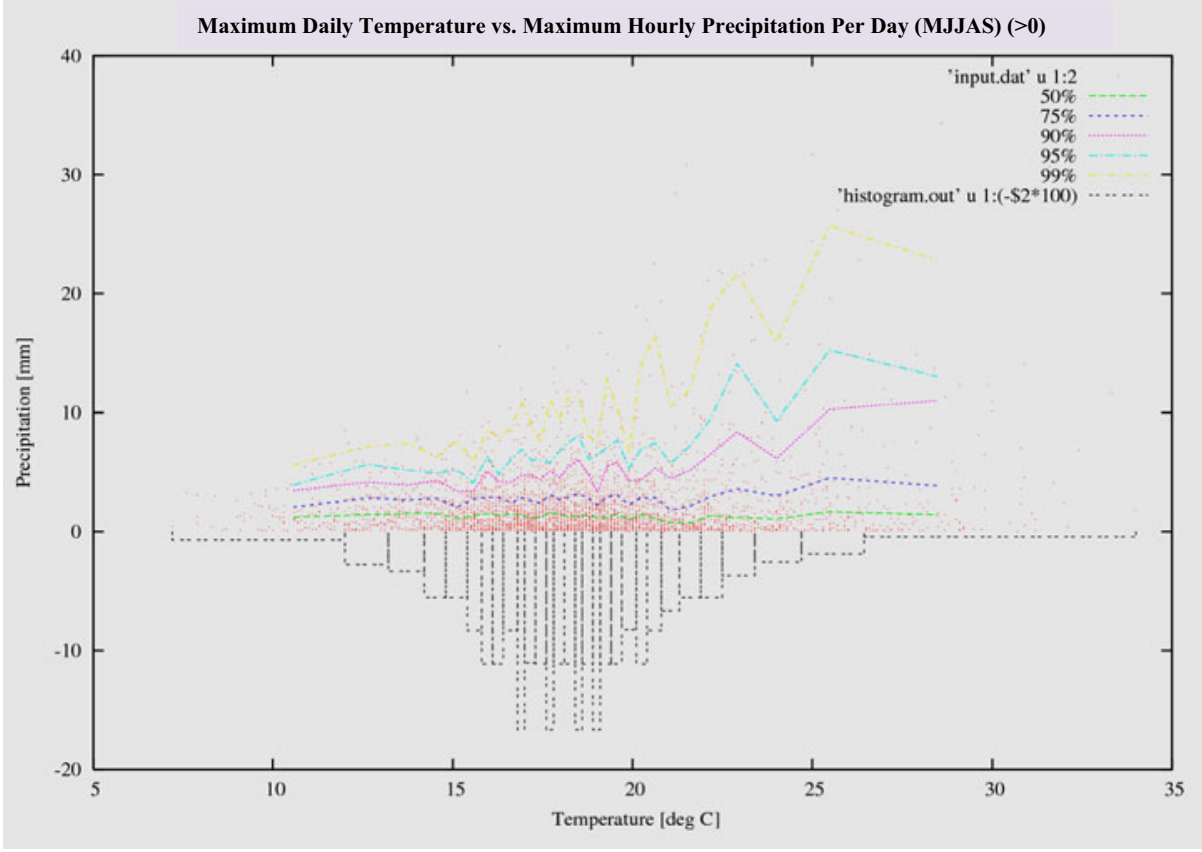

Fig. 6 Maximum daily temperature vs. maximum hourly precipitation per day for summer months (May-September) 


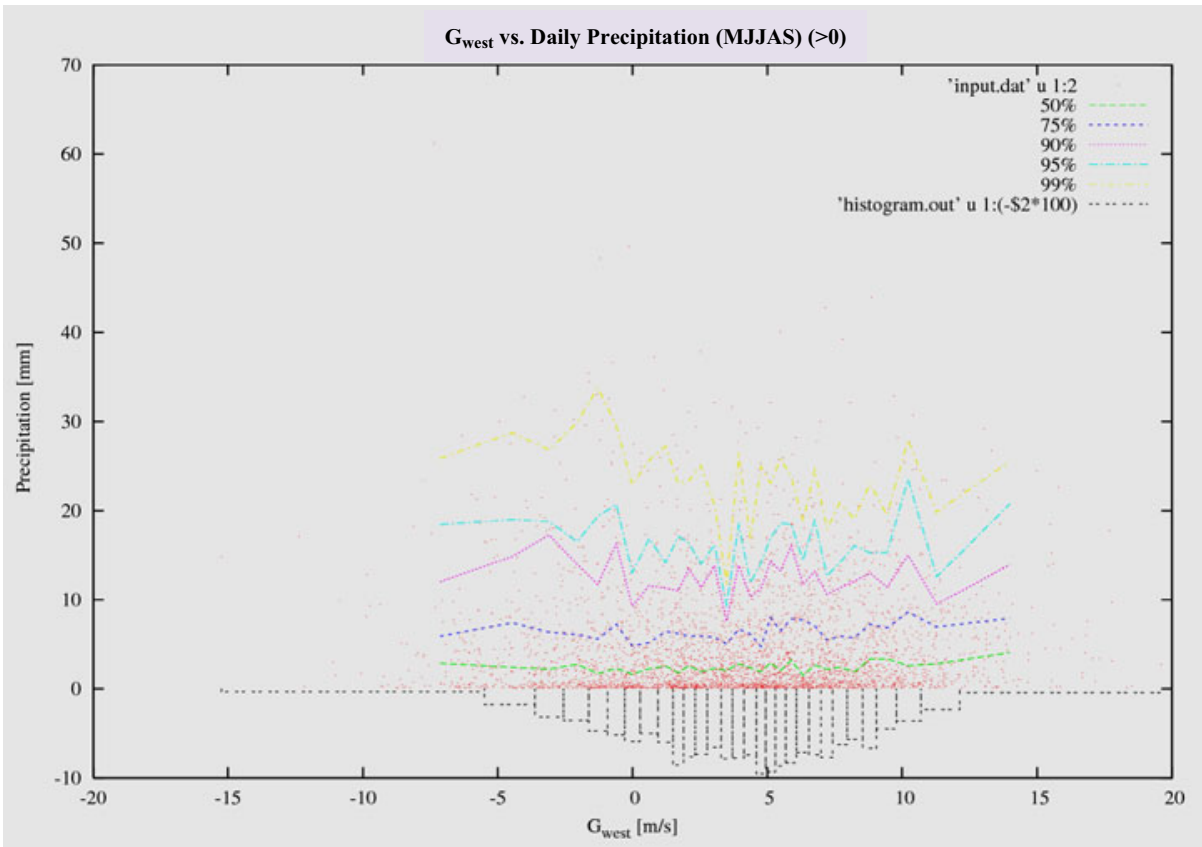

Fig. 7 G-west vs. daily precipitation for summer months (May until and including September)

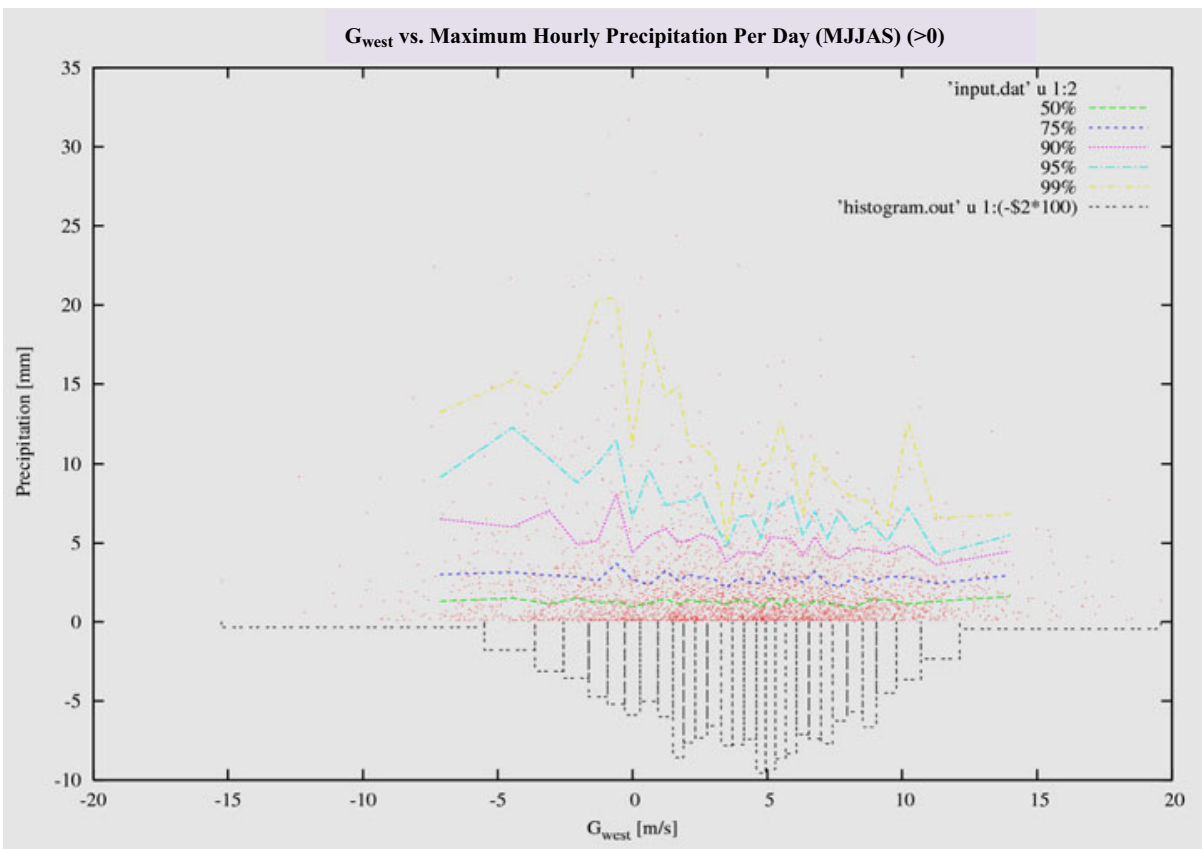

Fig. 8 G-west vs. maximum hourly precipitation per day for summer months (May until and including September) 
In the next step of our analysis, we started comparing points on the percentile lines for daily versus hourly precipitation. So we took the value of e.g. the $95 \%$ line of Figs. 5 and 6 for the same temperature and determined the ratio of daily versus hourly rainfall. We did this for the whole range of temperatures from $10-29^{\circ} \mathrm{C}$. And a similar analysis was made for the G-west.

Figure 9 is a plot of the relation between daily and maximum hourly precipitation in relation to maximum daily temperature plotted in Figs. 5 and 6. The thin-dashed line is the $95 \%$ ratio. This was constructed by dividing the $95 \%$ percentile line for daily precipitation (Fig. 5) by the $95 \%$ percentile line for hourly precipitation (Fig. 6). If we assume a linear relation between these data points, the result is the bolddashed line which gives the ratio of daily to maximum hourly precipitation versus maximum daily temperature. A change in ratio indicates a different relation with maximum daily temperature and therefore a different relation between daily and hourly precipitation. The linear equation for the bold-dashed line in Fig. 9 is,

$$
\begin{gathered}
\mathrm{y}_{95}=-0.16 \mathrm{x}_{95}+5.59 \\
\mathrm{x}=\text { maximum temperature in }{ }^{\circ} \mathrm{C} \\
\mathrm{y}=\text { ratio of daily to hourly precipitation }
\end{gathered}
$$

A similar calculation was made for the $99 \%$ percentile line ratio, which is represented by the solid line. The linear equation for the solid line is,

$$
\mathrm{y}_{99}=-0.18 \mathrm{x}_{99}+5.78
$$

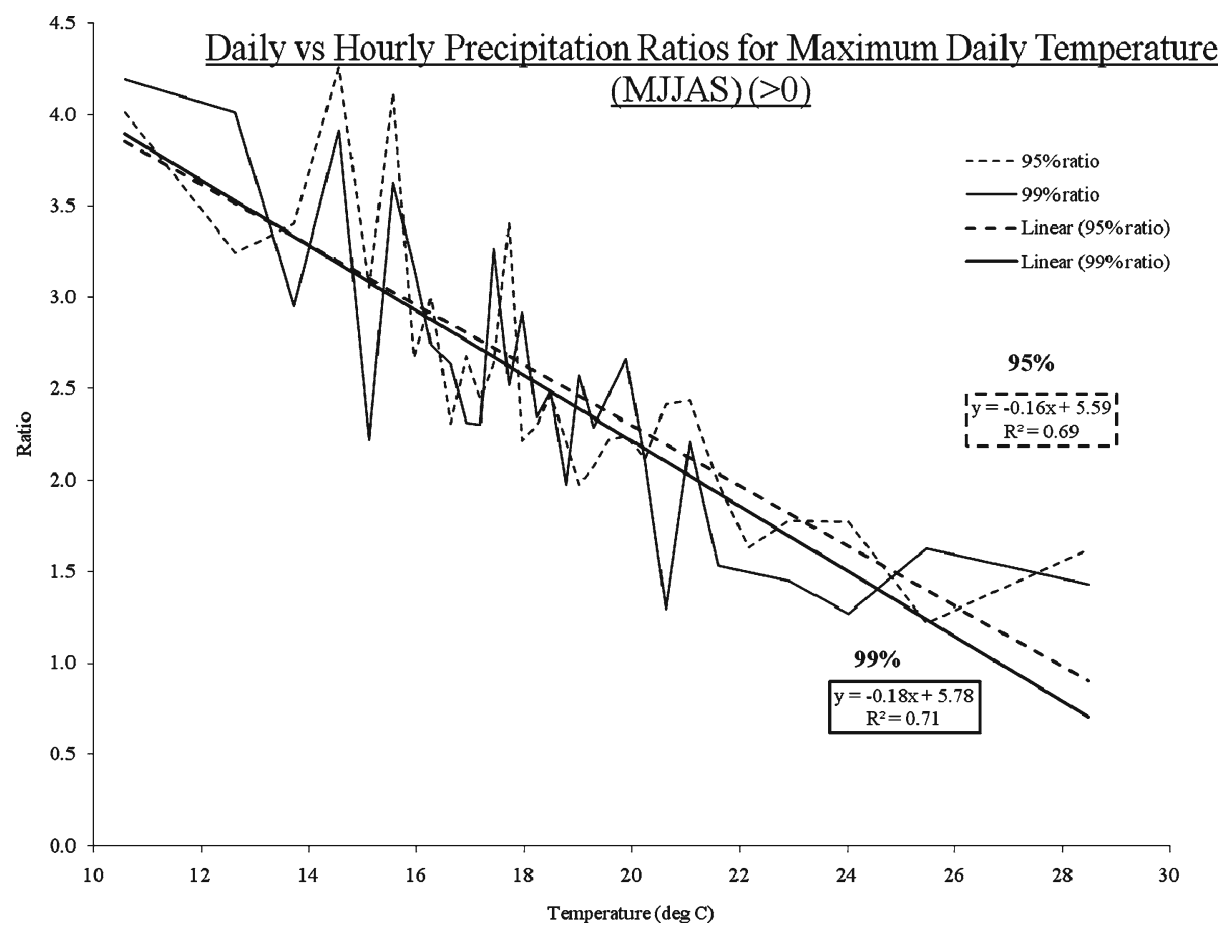

Fig. 9 Daily/maximum hourly precipitation ratios in relation to maximum daily temperature for summer months (May-September). The bold-dashed line is the regression value of 0.69. The solid line is the regression value of 0.71 
Figure 10 is a similar representation as shown in Fig. 9, but now in relation to G-west. The bold-dashed line gives the ratio of daily to hourly precipitation for $95 \%$ percentile line versus G-west;

$$
\begin{gathered}
\mathrm{y}_{95}=0.09 \mathrm{x}_{95}+1.99 \\
\mathrm{x}=\mathrm{G}-\text { west in } \mathrm{m} / \mathrm{s} \\
\mathrm{y}=\text { ratio of daily to hourly precipitation }
\end{gathered}
$$

The same was done for the $99 \%$ percentile line ratio (solid line);

$$
\mathrm{y}_{99}=0.08 \mathrm{x}_{99}+1.92
$$

Figures 9 and 10 show that the ratios of extreme daily to hourly precipitation for temperature and G-west are certainly not constant. The higher the temperature the closer this ratio between daily and maximum hourly rainfall approaches the value 1 (which means that all daily rainfall occurs within $1 \mathrm{~h}$ ). With strong westerly winds, daily rainfall is much higher than the maximum hourly rainfall.

Now, a relation has been established for extreme daily and hourly precipitation with the explanatory climate variables average daily temperature and G-west. These relations allow us to transform design storms and existing time series of hourly rainfall to new, synthetic series of rainfall under the assumption of a certain climate change scenario. Synthetic series or design storms can now be produced with the aid

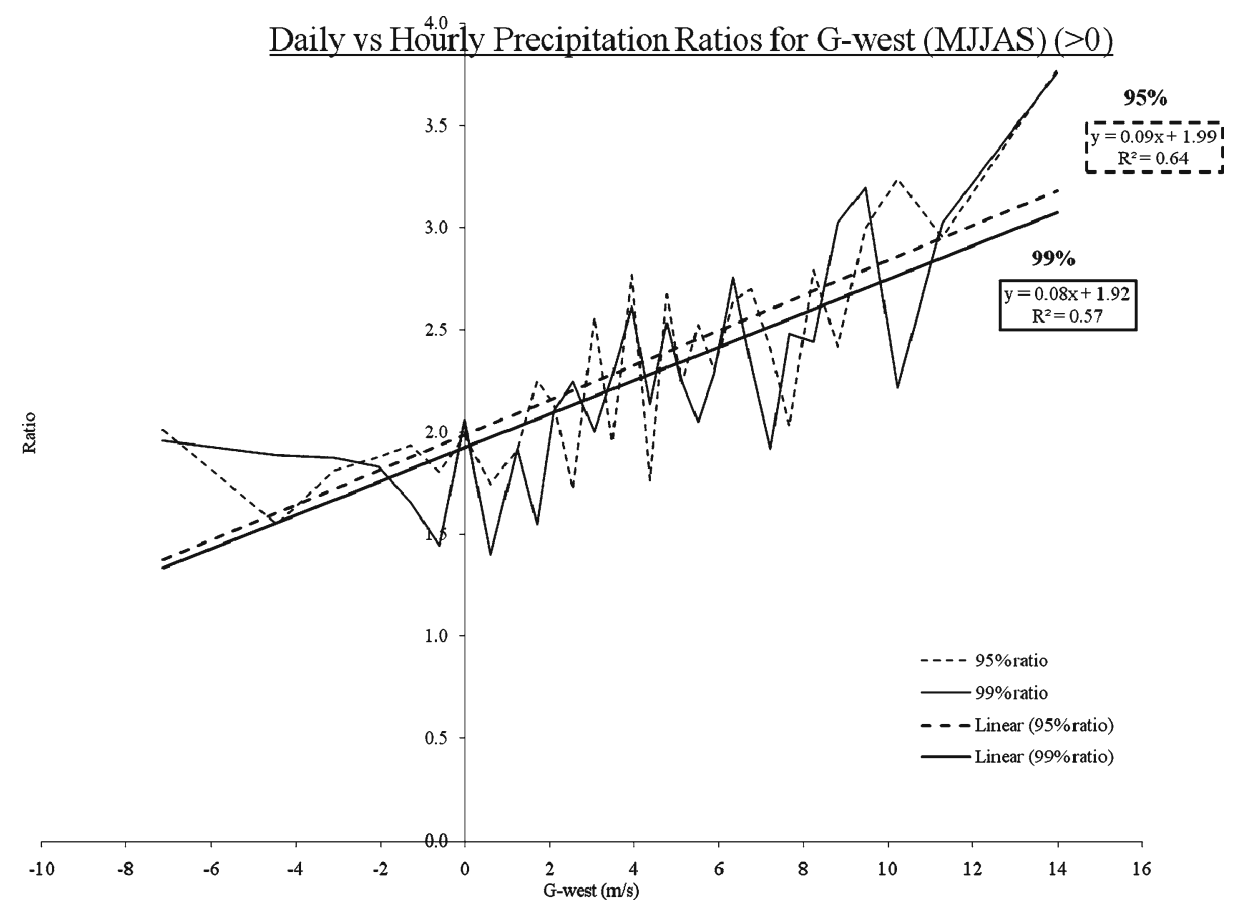

Fig. 10 Daily/maximum hourly precipitation ratios in relation to G-west for summer months (MaySeptember). The bold-dashed line is the regression value of 0.64 . The solid line is the regression value of 0.57 
of the four KNMI'06 climate scenarios using projected daily precipitation, G-West, and maximum daily temperature.

\section{Conclusion and outlook}

Based on the KNMI'06 climate scenarios, projections have been made for daily precipitation events for the time horizons 2050 and 2100. The methodology described above enables us to project these daily precipitation events into maximum hourly precipitation events. By examining historical data and analyzing the relationships between precipitation, at both daily and maximum hourly time scales, and explanatory climate variables, it was possible to determine a ratio to apply to daily precipitation projections that result in maximum hourly precipitation projections. Interestingly, although correlations between explanatory variables and precipitation were relatively weak, the correlation between explanatory variable and the daily/hourly precipitation ratio is strong. This strong correlation is the main finding of this paper.

A useful extension of this research would be construction of synthetic maximum hourly precipitation. This extension would allow us to transform design storms and existing time series of hourly rainfall into new synthetic series taking into account climate change scenario's. Eventually, as a second extension, these synthetic data can be used as input for an urban drainage model. With such a drainage model and synthetic data for design storms or design series the effects of climate change on the systems' performance can be assessed and the efficiency of adaptive measures can be investigated.

Open Access This article is distributed under the terms of the Creative Commons Attribution Noncommercial License which permits any noncommercial use, distribution, and reproduction in any medium, provided the original author(s) and source are credited.

\section{References}

Chang CB (1998) A case study of excessive rainfall forecasting. Meteorol Atmos Phys 66(3-4): 215-227

Doswell CA III, Brooks HE, Maddox RA (1996) Flash flood forecasting: an ingredients-based methodology. Weather Forecast 11:560-581

Gallego MC, García JA, Vaquero JM (2005) The NAO signal in daily rainfall series over the Iberian Peninsula. Clim Res 29:103-109

Graf WL (1977) Network characteristics in suburbanizing streams. Water Resour Res 13(2):459-463

Heijboer D, Nellestijn J (2002) (KNMI), Klimaatatlas Van Nederland, De Normaalperiode 19712000, Elmar B.V., Rijswijk

Kundzewicz ZW, Mata LJ, Arnell NW, Döll P, Kabat P, Jiménez B, Miller KA, Oki T, Sen Z, Shiklomanov IA (2007) Freshwater resources and their management. In: Parry ML, Canziani OF, Palutikof JP, van der Linden PJ, Hanson CE (eds) Climate change 2007: impacts, adaptation and vulnerability. Contribution of working group II to the fourth assessment report of the intergovernmental panel on climate change. Cambridge University Press, Cambridge, UK, pp 173-210

Lenderink G, van Meijgaard E (2008) Increase in hourly precipitation extremes beyond expectations from temperature changes. Nature Geoscience 1(8)

Meehl GA, Arblaster JM, Tebaldi C (2005) Understanding future patterns of increased precipitation intensity in climate model simulations. Geophys Res Lett 32:L18719. doi:10.1029/2005GL023680

Meehl GA, Stocker TF et al (2007) Global climate projections. In: Solomon S, Qin D, Manning M, Chen Z, Marquis M, Averyt KB, Tignor M, Miller HL (eds) Climate change 2007: 
the physical science basis. Contribution of working group I to the fourth assessment report of the intergovernmental panel on climate change. Cambridge University Press, Cambridge, pp 747-846

Mitchell RM, Phillips ID (2006) Warm season extreme precipitation events at Sunderland 1940-2000, the royal meteorological society. Weather $61(8)$

Ntelekos AA, Smith JA, Baeck ML, Krajewski WF, Miller AJ, Goska R (2008) Extreme hydrometeorological events and the urban environment: dissecting the 7 July 2004 thunderstorm over the Baltimore MD Metropolitan Region. Water Resour Res 44:W08446. doi:10.1029/2007WR006346

Overeem A, Buishand A, Holleman I (2008) Rainfall depth-duration-frequency curves and their uncertainties. J Hydrol 348:124-134

Phillips ID, McGregor GR (2001) The relationship between synoptic scale airflow direction and daily rainfall: a methodology applied to Devon and Cornwall, South West England. Theor Appl Climatol 69:179-198

Royal Netherlands Meteorological Institute (2006) Climate change scenarios 2006 for The Netherlands. Scientific Report, WR 2006-01. De Bilt, The Netherlands

Smith JA, Baeck ML, Morrison JE, Sturdevant-Rees P, Turner-Gillespie DF, Bates PD (2002) The regional hydrology of extreme floods in an urbanizing drainage. J Hydrometeorol 3(3):267-282

STOWA (2004) Statistiek van Extreme Neerslag in Nederland, report nr. 26, Hageman Fulfilment. http://www.stowa.nl/uploads /themadownloads2/mID_4910_cID_3900_STOWA_rapport_2004_ 26.pdf. Accessed June 292007

Waters D, Watt WE, Marsalek J, Anderson BC (2003) Adaptation of a storm drainage system to accommodate increased rainfall resulting from climate change. J Environ Plan Manag 46:755-770 